Intensive Care Med (1990) 16:33-40

IntensiveCare

\title{
Alveolar pressure during high-frequency jet ventilation
}

\author{
A. J. van Vught ${ }^{1,2}$, A. Versprille ${ }^{1}$ and J.R.C. Jansen ${ }^{1}$ \\ ${ }^{1}$ Pathophysiological Laboratory, Department of Pulmonary Diseases, Erasmus University, Rotterdam, The Netherlands \\ 2 Pediatric Intensive Care Unit, University Children's Hospital "Het Wilhelmina Kinderziekenhuis", Utrecht, The Netherlands \\ Received: 15 July 1989; accepted: 15 October 1989
}

\begin{abstract}
We studied the influence of ventilatory frequency $(1-5 \mathrm{~Hz})$, tidal volume, lung volume and body position on the end-expiratory alveolar-to-tracheal pressure difference during high-frequency jet ventilation (HFJV) in Yorkshire piglets. The animals were anesthetized and paralysed. Alveolar pressure was estimated with the clamp off method, which was performed by a computer controlled ventilator and which had been extensively tested on its feasibility. The alveolar-to-tracheal pressure difference increased with increasing frequency and with increasing tidal volume, the common determinant appearing to be the mean expiratory flow. The effects in prone and in supine position were similar. Increasing thoracic volume decreased the alveolar-to-tracheal pressure difference indicating a dependence of this pressure difference on airway resistance. We concluded that the main factors determining the alveolar-to-tracheal pressure difference $(\Delta \mathrm{P})$ during HFJV are expiratory flow $\left(\mathrm{V}_{E}^{\prime}\right)$ and airway resistance $(R), \Delta P \simeq V_{E}^{\prime} \times R$.
\end{abstract}

Key words: Intrinsic PEEP - Ventilatory pattern Lung volume - Lung stretch - piglets

During high-frequency ventilation (HFV), an increase in alveolar pressure will follow when the expiratory time becomes too short for the alveolar pressure to fall to the preset end-expiratory level [1-3]. As a consequence, lung volume and alveolar pressure will increase until a new equilibrium is established between insufflation and expiration [2-18]. In previous studies we obtained evidence that such an increase in lung volume suppresses spontaneous breathing activity in piglets [17, 18]. Additionally, we found more suppression of breathing activity during ventilation with higher tidal volumes and shorter expiratory times than expected from the rise in end-expiratory pressure (PEEP) measured in the trachea [18]. This additional suppression could be ascribed to an extra increase in end-expiratory alveolar volume and end-expiratory alveolar pressure superimposed on the increase due to PEEP [4, 7, 9, 10, 12-16].

To estimate the increase in alveolar pressure due to high-frequency jet ventilation (HFJV) as such, we analysed in piglets the effects of changes in ventilatory frequency and tidal volume on the difference between end-expiratory alveolar and tracheal pressure. To compare the effects for a given geometry of the airways, i.e. a constant airway resistance, we kept end-expiratory thoracic volume constant at baseline level by raising external pressure in a body box. The baseline level was the end-expiratory volume during intermittent positive pressure breathing at a rate of 10 per minute.

We additionally studied the influence of a change in airway resistance on these effects by changing lung volume [19].

Larger differences between alveolar pressure and tracheal pressure have been found in the lateral position compared with those in the supine position [13].

These differences have been attributed to changes in airway impedance due to changes in airway geometry. To test whether position per se could have an influence we compared in a part of our experiments the effects of a supine position with those in a prone position under conditions of a constant thoracic volume.

We determined alveolar pressure from the rise in tracheal pressure under stop flow conditions after simultaneously clamping off the inspiratory and expiratory tubes $[8,10,13,20-25]$. A feasibility study of this technique has never been reported. Therefore, we have first tested the validity of this technique. 


\section{Methods}

\section{Preparation}

Yorkshire piglets, $5-7$ weeks old and weighing $9-12 \mathrm{~kg}$, were anesthetized with pentobarbital sodium (induction dose $30 \mathrm{mg} \cdot \mathrm{kg} \cdot{ }^{-1}$ intraperitoneally, maintainance dose $8.5 \mathrm{mg} \cdot \mathrm{kg}^{-1} \cdot \mathrm{h}^{-1}$ i.v.). The animals were placed in supine position on a thermocontrolled operating table. Rectal temperature was kept at approximately $39^{\circ} \mathrm{C}$. After tracheostomy the trachea was connected via a Y-cannula with a jet nozzle in between the inspiratory and expiratory limb to inspiratory and expiratory tubes (Fig. 1). A catheter was placed into the right common carotid artery for blood pressure monitoring and blood sampling. Via the right external jugular vein a 4-lumen catheter was inserted into the superior caval vein for infusions. Before venous cannulation was started the animals were ventilated with PEEP to prevent air embolism during cannulation. After cannulation they were paralysed with d-tubocurare, $0.2-0.4 \mathrm{mg} \cdot \mathrm{kg}^{-1} \cdot \mathrm{h}^{-1}$ i.v. after a loading dose of $0.2-0.4 \mathrm{mg} \cdot \mathrm{kg}^{-1}$ in $6-12$ minutes, to prevent spontaneous breathing activity during the observations. The animals were placed in a body box in which the pressure could be varied by a continuous airflow through a water seal. Heparin was administered each hour $\left(250 \mathrm{IU} \cdot \mathrm{kg}^{-1}\right.$ i.v.) throughout the experiments.

\section{Measurements}

Tracheal pressure was measured via a fluid filled catheter provided with side holes. Arterial and tracheal pressures were measured with Statham P23De transducers. Arterial pressure was measured relative to atmospheric pressure at the manubrium level. Zero-reference of intratracheal pressure was taken during apnea. The tracheal catheter-transducer system followed pressure changes identically up to $5 \mathrm{~Hz}$ [17]. A mercury strain gauge was placed around the thorax just caudal to the forelegs to measure changes in thoracic volume. Calibration was performed by a slow insufflation of a known volume of gas during low frequency ventilation. Ventilatory (tidal) volume was calculated by the integration of expiratory air flow over the whole ventilatory cycle. Airflow was measured behind a mixing box in the expiratory tube (Fleisch pneumotachograph type 0 Godart). In this mixed expiratory air $\mathrm{CO}_{2}$ and $\mathrm{O}_{2}$ concentrations were measured with a mass spectrometer (Perkin-Elmer MGA 1100). $\mathrm{PO}_{2}, \mathrm{PCO}_{2}$ and acid-base variables in blood were determined by means of an automatic blood gas analyser (Radiometer ABL3). Pressure in the body box was measured with a Hewlett Packard 270 gas pressure transducer.

The electrocardiogram and the aortic, tracheal, body box pressures and strain gauge signal together with the expired volume were simultaneously recorded on a Hewlett Packard 7758A chart recorder.

\section{Experimental procedures}

The experimental set-up is shown in Fig. 1. The animals were ventilated with a high-frequency jet ventilator developed in our laboratory. The ventilator consisted of 8 solenoid valves with precalibrated reduction valves arranged in parallel and allowing variations in inspiratory flow without changes in driving pressure. The valves were activated by a microprocessor in such a way that tidal volume, respiratory cycle time and thus respiratory frequency and inspiratory and expiratory fractions could be changed independently.

After a preset number of ventilatory cycles the microprocessor was programmed to interpose a special cycle which was used during HFJV as the clamp off procedure. This special cycle was characterized by a duration of $5000 \mathrm{~ms}$ and a closure of both inspiratory and expiratory valves.

The ventilator was fed with $40 \%$ oxygen in air (Ohio gas mixer) under a driving pressure of 3 bar. After the surgical procedures the animals were ventilated with intermittent positive pressure (IPPV). This IPPV served as baseline conditions throughout the experiments: frequency $10 \mathrm{~min}^{-1}$, inspiratory-expiratory ratio 1 and a tidal volume between $170-270 \mathrm{ml}$. Arterial $\mathrm{PCO}_{2}$ with this ventilatory pattern ranged from $28.6-47.5 \mathrm{~mm} \mathrm{Hg}$.

In a group of six piglets (group I) three series of experiments were carried out.

In series one five different observation periods of HFJV with different cycle times were imposed in a random order: $1000 \mathrm{~ms}$, $500 \mathrm{~ms}, 300 \mathrm{~ms}, 250 \mathrm{~ms}$ and $200 \mathrm{~ms}$, corresponding to respectively $1 \mathrm{~Hz}, 2 \mathrm{~Hz}, 3.3 \mathrm{~Hz}, 4 \mathrm{~Hz}$ and $5 \mathrm{~Hz}$. Tidal volume was kept constant within narrow limits at about $40 \mathrm{ml}$ and inspiratory time was maintained at $100 \mathrm{~ms}$. In between each observation the piglets were ventilated under the previously mentioned baseline condition for at least $3 \mathrm{~min}$ to revert atelectasis. Moreover, the lungs were expanded by three or more sighs.

The increases in end-expiratory thoracic volume were restored to the preceding baseline level by an increase in pressure in the body box under the guidance of the mercury strain gauge.

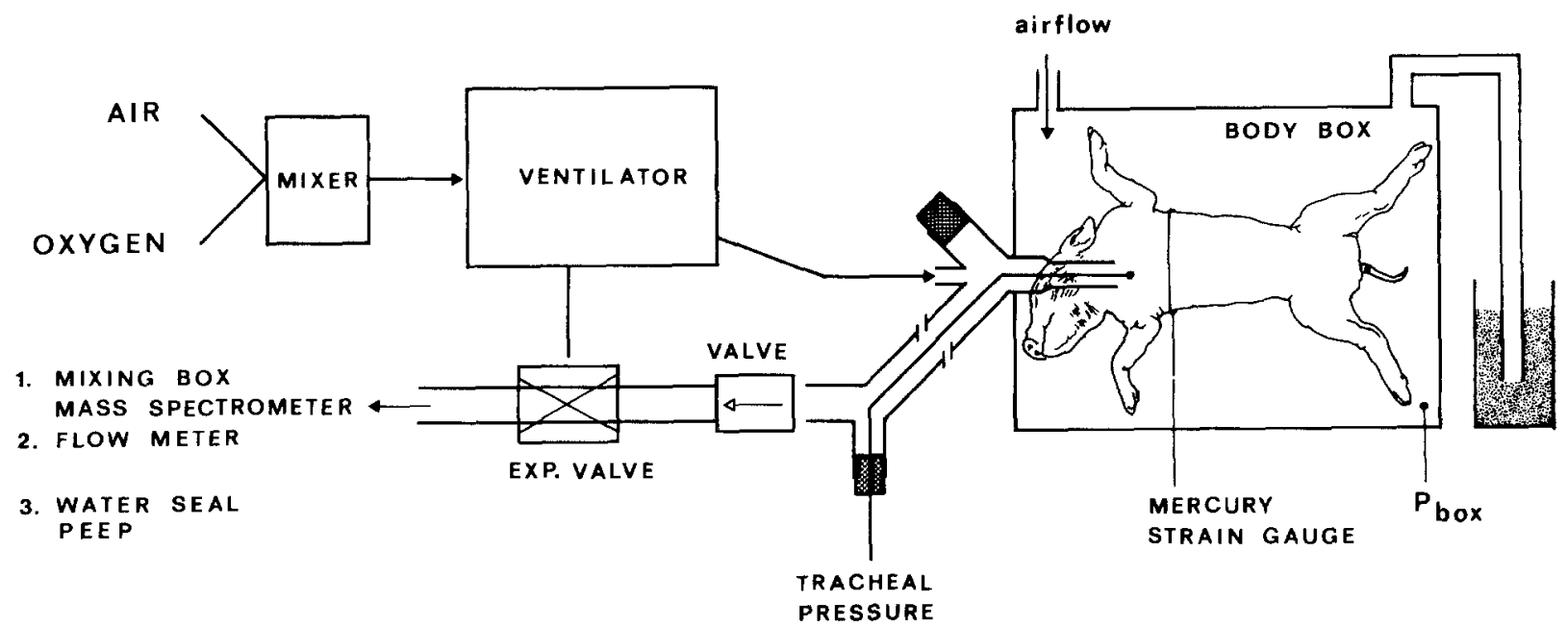

Fig. 1. Experimental set-up. Thoracic volume was adjusted by varying the pressure in the body box, using a water seal and a continuous air flow. See text for operational explanation 
Ventilation with a cycle time of $1000 \mathrm{~ms}(1 \mathrm{~Hz})$ resulted in a gradual decrease in thoracic volume which was corrected by the application of PEEP.

Within 2 min a series of clamp off procedures was performed with intervals of 20 ventilatory cycles. From such a series only that observation was selected in which the recovered volume was equal or close to the baseline volume. After the series of observations the trachea was sucked out to remove secretions.

In series two five different tidal volumes between 20 and $70 \mathrm{ml}$ were applied randomly. Baseline ventilation was performed in between each observation. The cycle time was kept constant at $300 \mathrm{~ms}$. $(3.3 \mathrm{~Hz})$ and inspiratory time at $100 \mathrm{~ms}$. Again end-expiratory thoracic volume was recovered to baseline level using the pressure in the body box. All other procedures were performed as in series one.

In series three a constant pattern of ventilation was applied at different levels of thoracic volume. The ventilatory pattern was characterized by a tidal volume of about $60 \mathrm{ml}$, a cycle time of $300 \mathrm{~ms}$ and a inspiratory time of $100 \mathrm{~ms}$. After setting this ventilatory pattern end-expiratory thoracic volume was restored to the baseline level with a pressure increase in the body box. Subsequently, PEEP was applied and thoracic volume was varied in a random order in five steps from zero to about $500 \mathrm{ml}$ above the baseline value. In between each step the animals were ventilated with the baseline conditions. At each level the series of clamp off procedures was applied as described in series one.

In each animal of group I the three series of experiments were performed in a different order, so all six possible orders were represented.

In a second group of five piglets (group II) series one of group I was performed in two different body positions in the order supine, prone and supine again. In four of these animals the clamp off procedure was performed twice with an interval of five minutes. During the interval HFJV was maintained and end-expiratory thoracic volume was kept constant by adjusting the pressure in the body box.

All animals were autopsied at the end of the experiment to check the position of the catheters, the presence of pneumothorax and the degree of atelectasis. There was a variable degree of atelectasis. In three animals we found a subpleural hematoma and in one animal a few air bubbles were found in the right pleural cavity.

\section{Data analysis}

When the expiratory time becomes too short for the tracheal pressure to fall to atmospheric level tracheal pressure rises. A rise in tracheal pressure will increase alveolar pressure to the same extent. Therefore, the clamp off pressure and the body box pressure were corrected for this tracheal pressure rise to avoid an offset of both values. Such an offset should improve the correlation coefficient without implying any real significance. For validating the clamp off technique the difference between tracheal pressure during an end-expiratory clamp off and the end-expiratory tracheal pressure $(\Delta P$, clamp off) was compared with the difference between the pressure in the body box and the end-expiratory tracheal pressure $(\Delta \mathrm{P}$, box $)$. Such a $\Delta \mathrm{P}$ was considered to be the effective pressure gradient for flow at end-expiration during HFJV.

To relate both $\Delta \mathbf{P}$ values, orthogonal regression equations for two independent variables according to Deming were applied [26]. $\Delta P$, clamp off values were related to the imposed jet frequencies and tidal volumes respectively by linear regression analysis. Differences between $\Delta \mathrm{P}$, clamp off and $\Delta \mathrm{P}$, box, the effect of time on these differences and the effects of mean expiratory flow on $\Delta P$, clamp off have been tested statistically with repeated measures (animals, time) analysis of $(\mathrm{co})$ variance with frequency, tidal volume or mean expiratory flow as covariates. Differences in slope have been tested first and in case of equal slopes differences in position (intercept) were tested.

\section{Results}

\section{Test of clamp off method}

When $\Delta \mathrm{P}$, clamp off was plotted against $\Delta \mathrm{P}$, box an excellent linear correlation was found. However, there was a small shift from the line of identity indicating the $\Delta \mathrm{P}$, clamp off was slightly higher than the $\Delta \mathrm{P}$, box (Fig. 2). The regression equation of all paired measurements, obtained by variation of ventilatory frequency, was calculated as $\mathrm{Y}=0.95+0.88 \mathrm{X}, \mathrm{r}=0.92$. The slope of this equation is not significantly different from 1, i.e. the slope of the line of identity. However, when the paired measurements were fitted by a line with a slope of 1 , this line was slightly but significantly shifted upwards with a pressure value of $0.8 \mathrm{~cm} \mathrm{H}_{2} \mathrm{O}$ $(p=0.001)$. Comparable results were found for changing tidal volume $(\mathrm{Y}=0.81+0.80 \mathrm{X}, \mathrm{r}=0.90$ with a non-significant shift of $0.3 \mathrm{~cm} \mathrm{H}_{2} \mathrm{O}$ ) and for changing ventilatory frequency in prone position $(\mathrm{Y}=0.91+0.85 \mathrm{X}, \mathrm{r}=0.90$ with a shift of $0.8 \mathrm{~cm}$ $\mathrm{H}_{2} \mathrm{O}, p<0.001$ ).

We found a significant effect of time on the relationship (Fig. 3). Within two minutes after the onset of HFJV the relationship was close to and not significantly different from the line of identity $(\mathrm{Y}=0.79$ $+0.68 \mathrm{X}, \mathrm{r}=0.97$ ). Five minutes later the relationship

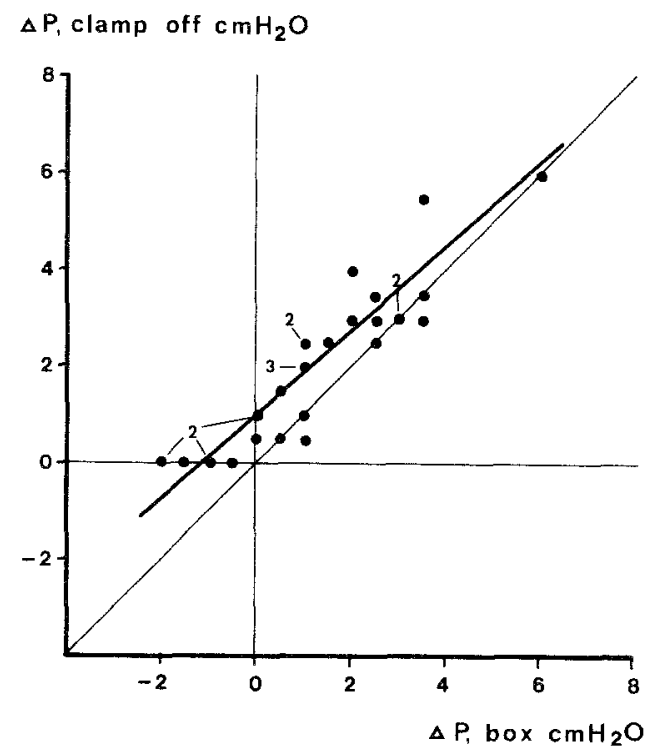

Fig. 2. The difference between tracheal pressure during an end-expiratory clamp off procedure and the end-expiratory tracheal pressure during ventilation ( $\Delta \mathrm{P}$, clamp off) plotted against the corresponding differences between the pressure in the body box and the end-expiratory tracheal pressure $(\Delta \mathbf{P}$, box $)$ in six animals of group I, ventilated with varying frequencies. Numbers indicate overlapping points. The thick line represents the orthogonal regression line 
$\Delta P$ clamp off $\mathrm{cm} \mathrm{H}_{2} \mathrm{O}$

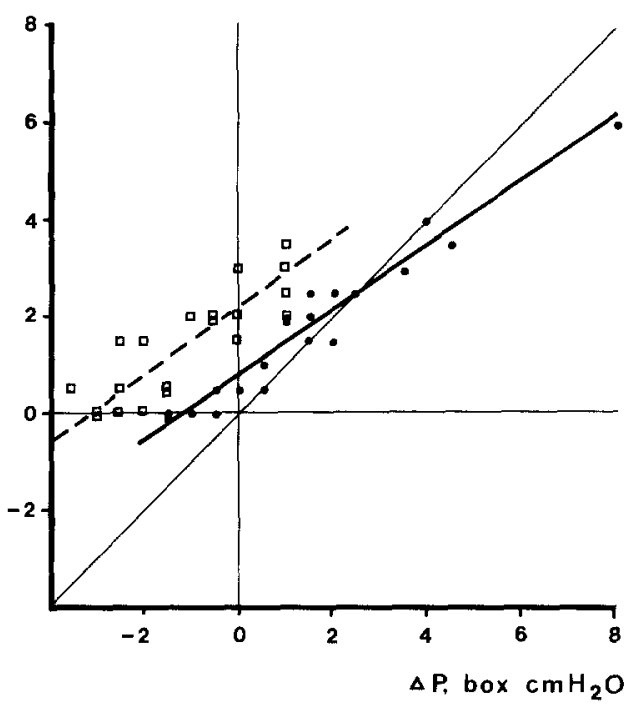

Fig. 3. The relation between $\Delta P$, clamp off and $\Delta P$, box (see Fig. 2) within $2 \mathrm{~min}$ after the onset of ventilation (thick solid line) and 5 min later (dashed line) in four animals of group II, ventilated in supine position with varying frequencies

was $\mathrm{Y}=2.20+0.71 \mathrm{X}, \mathrm{r}=0.85$, with a significant shift $(p<0.001)$ to the left (or upwards). In the other observations of group II in the prone position and again in the supine position respectively identical results were obtained. Thus, immediately after the onset of ventilation both methods of measuring alveolar pressure appeared to be identical. For various reasons we have taken $\Delta \mathrm{P}$, clamp off as the substitute of the alveolarto-tracheal pressure gradient during HFJV.

\section{Effects of ventilatory frequency, tidal volume and} lung volume

In group I we found linear relationships between $\Delta \mathrm{P}$, clamp off and ventilatory frequency (Fig. $4 \mathrm{a}$ ) and tidal volume (Fig. 4b), respectively.

In both series we calculated the mean expiratory flow from the tidal volume devided by the expiratory time. Both series yielded linear relationships between $\Delta P$, clamp off and mean expiratory flow (Fig. $4 \mathrm{c}$ ). The slope of the relationship in both series was identical. Nevertheless there was a small shift of $0.3 \mathrm{~cm} \mathrm{H} \mathrm{H}_{2} \mathrm{O}$ $(p<0.05)$ between the two regressions lines.

In Fig. $5 \Delta \mathrm{P}$, clamp off at different levels of endexpiratory thoracic volume, as found in the six animals of group $I$ is shown. End-expiratory volume during IPPV was the baseline condition. In all animals $\Delta P$, clamp off decreased with higher thoracic volume. Close to the baseline value $\Delta \mathrm{P}$, clamp off increased progessively with a fall in thoracic volume in two of

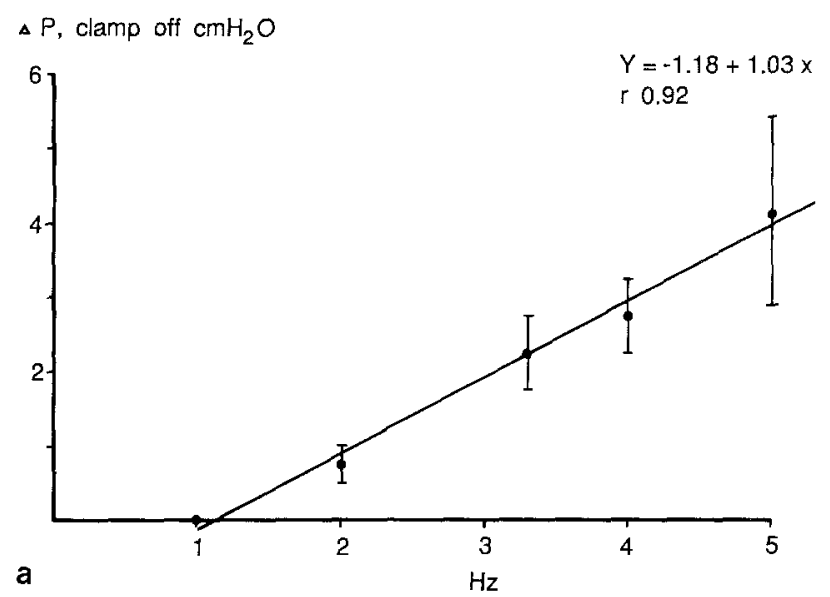

$\triangle P$, clamp off $\mathrm{cmH}_{2} \mathrm{O}$
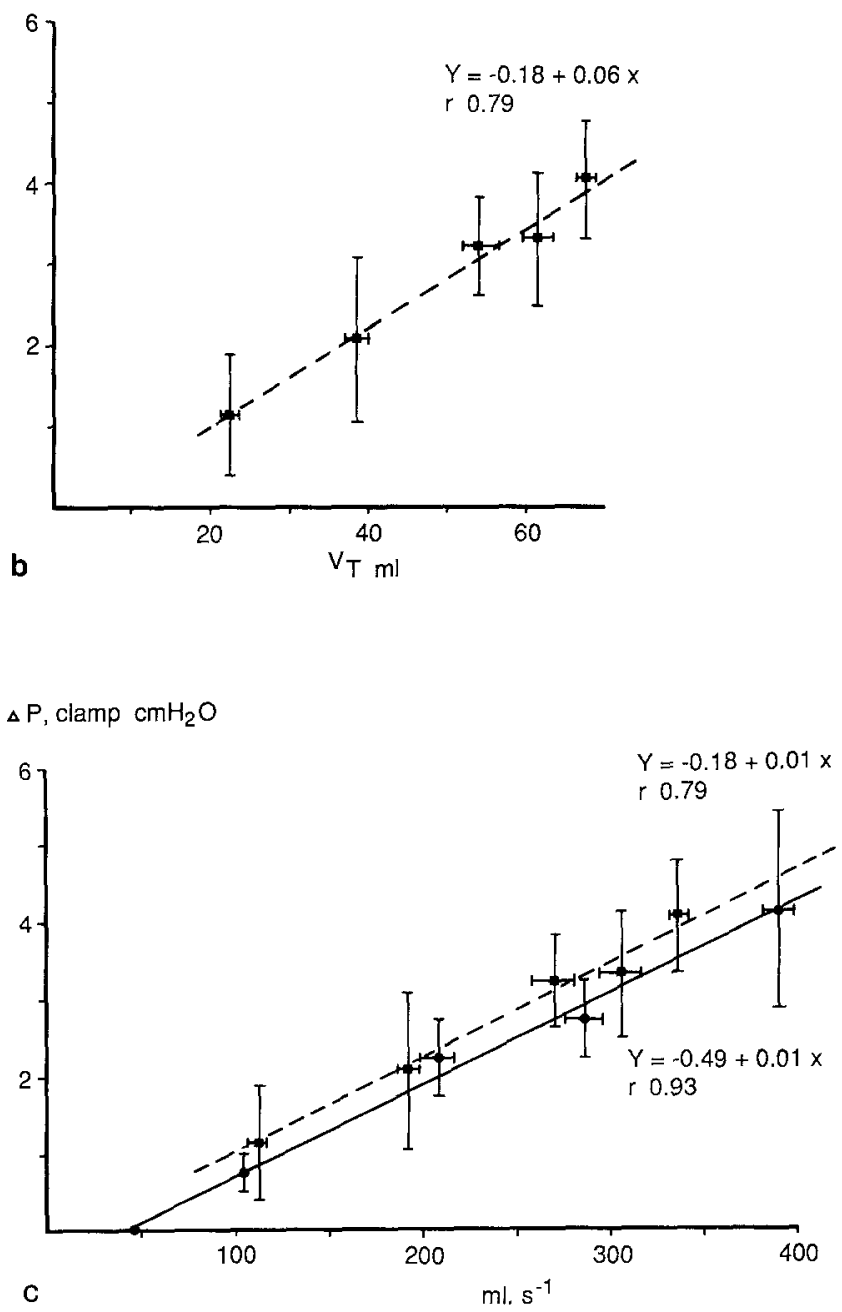

Fig. 4. $\Delta \mathrm{P}$, clamp off plotted as a function of jet frequency (a) and tidal volume (b) in six animals of group I, ventilated in supine position. From both relationships $\Delta P$, clamp off was derived as function of mean expiratory flow (c). The lines represent the linear regression lines calculated from all individual points. Bars represent 1 SD 
$\triangle P$, clamp off $\mathrm{cmH}_{2} \mathrm{O}$

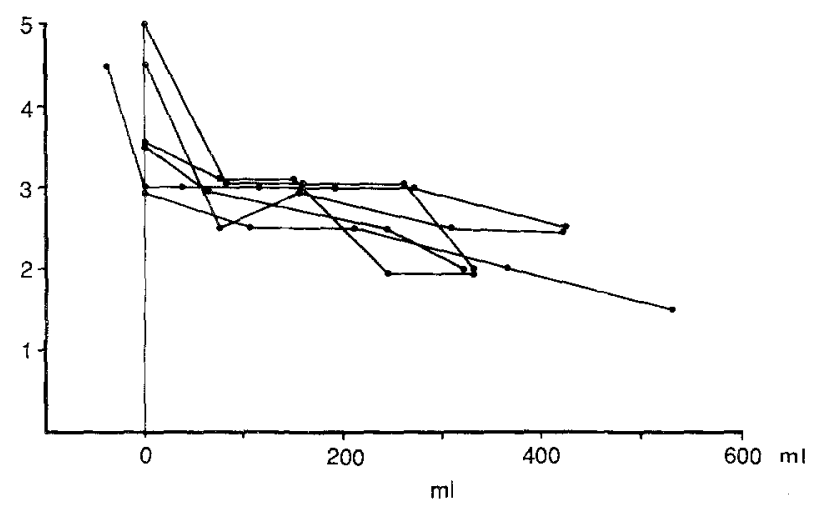

Fig. 5. $\Delta P$, clamp off as a function of the increase in end-expiratory thoracic volume in the six individual animals of group I ventilated in supine position at a constant frequency $(3.3 \mathrm{~Hz})$ and with a constant inspiratory time $(100 \mathrm{~ms})$ and constant tidal volume $(60 \mathrm{ml})$. Baseline volume is defined in the text

the animals. In one animal thoracic volume had been compressed with the box pressure to a level below the baseline volume, which elicited also a sharp rise in $\Delta \mathrm{P}$, clamp off.

\section{Influence of body position}

$\Delta \mathrm{P}$, clamp off in prone and supine positions was measured at different ventilatory frequencies in the five animals of group II. Tidal volume, inspiratory time and end-expiratory thoracic volume were kept constant. Linear regression lines relating $\Delta \mathrm{P}$, clamp off and ventilatory frequency were calculated as $\mathrm{Y}=-1.48+1.18 \mathrm{X} \quad(\mathrm{r}=0.80)$ for supine position, $Y=-0.98+0.86 \times(r=0.93)$ for prone position and $Y=-1.04+0.99 \times \quad(r=0.92)$ for supine position again. These relationships were not statistically different from each other.

\section{Discussion}

\section{The clamp off method}

Several authors have studied the clamp off method for the estimation of alveolar pressure $[8,10,13,20$, 23-25]. However, the method has not been validated satisfactorily yet, because there is no 'gold' standard.

Simon et al. [13] have found a close correlation $(r=0.96)$ between mean alveolar pressure estimated by the clamp off method and pleural pressure during high-frequency oscillation (HFO). However, this was studied in one dog only and the good correlation between the tracheal clamp off pressure and pleural pressure does not necessarily indicate an identity of this clamp off pressure and alveolar pressure.

Armengol et al. [4] compared the pressure found by the clamp off method during HFO in dogs with the pressure derived from a separately constructed quasistatic volume-pressure curve at a lung volume equal to that found during oscillation. The clamp off method indicated lower values than those found on the volume-pressure curve. This comparison was based on the assumption that respiratory muscle tone and lung and thoracic recoil forces were the same in both conditions. However, Pfenninger and Minder did not find such a similarity in the recoil forces [24]. Therefore, we conclude that lung volume cannot be derived from the pressure value during HFJV on the basis of the quasistatic volume-pressure curve.

In our study we compared the clamp off pressure with a body box pressure necessary to return thoracic volume to its baseline value. This baseline value was obtained when alveolar pressure and ambient air (i.e. body box) pressure were zero. The clamp off procedures were performed at the recovered baseline volume.

Figure 6 explains the theoretical basis for the comparison of the clamp off pressure with the body box pressure.

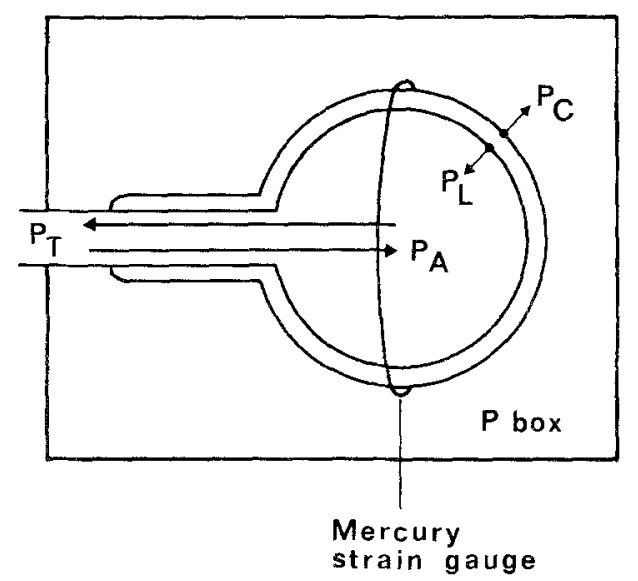

Fig. 6. Schematic drawing of the theoretical basis of the experimental set-up representing the trachea, the lumped alveolar space and the thoracic wall, situated in the body box (rectangle). Arrows indicate inspiratory and expiratory tidal volume, driven by the difference between tracheal pressure $\left(P_{T}\right)$ and alveolar pressure $\left(P_{A}\right)$. By varying the pressure in the body box $\left(P_{b o x}\right)$ thoracic volume can be adjusted. At a constant thoracic volume as indicated by the mercury strain gauge the thoracic recoil forces $\left(P_{C}\right)$ are constant. Provided the recoil forces of the lung $\left(P_{L}\right)$ are also constant, the pressure difference $P_{A}-P_{\text {box }}$ should be constant too. Muscle forces are zero because of paralysis 
When the respiratory muscles are paralysed, as was done in our experiments, alveolar pressure $\left(\mathrm{P}_{\mathrm{A}}\right)$ will be dependent on the recoil forces of the lung $\left(\mathrm{P}_{\mathrm{L}}\right)$, those of the thoracic cage $\left(\mathrm{P}_{\mathrm{C}}\right)$ and the ambient air pressure $\left(\mathrm{P}_{\text {box }}\right)$. At zero ambient air pressure and open airways $P_{A}=P_{L}+P_{C}$ where $P_{C}$ will have an opposite sign to $P_{L}$ [27]. We have called thoracic volume at this level the baseline value. When $\mathrm{P}_{\mathrm{A}}$ is raised lung volume will be increased and $P_{L}$ will be increased due to stretch of lung tissue. Then, $\mathrm{P}_{\mathrm{C}}$ will be decreased to zero and increased again with the same sign as $P_{L}$. When next $P_{b o x}$ is increased $P_{L}$ and $P_{C}$ will be decreased according to $\mathrm{P}_{\mathrm{A}}=\mathrm{P}_{\mathrm{L}}+\mathrm{P}_{\mathrm{C}}+\mathrm{P}_{\text {box }}$, causing a concomitant decrease in thoracic volume. When lung volume is recovered to its baseline value $P_{L}$ and $P_{C}$ will also be restored to their baseline levels under ideal conditions. Then, $\mathrm{P}_{\text {box }}$ reflects the rise of $\mathrm{P}_{\mathrm{A}}$.

In our experiments under these conditions tracheal pressure also rose above the zero level due to flow resistances in the expiratory part of the ventilatory system. Such a rise contributes to the rise in alveolar pressure. Because we were interested in the pressure difference over the airways, the clamp off pressure and the pressure in the body box were corrected for this tracheal pressure rise, giving $\Delta \mathrm{P}$, clamp off and $\Delta \mathrm{P}$, box respectively.

$\Delta \mathrm{P}$, clamp off plotted against $\Delta \mathrm{P}$, box yielded values close to the line of identity with high correlation coefficients for all ventilatory modes studied. We concluded that both methods were valid to estimate alveolar pressure, but we regarded the clamp off method superior to the body box method. With time passing on during HFJV small differences between both methods developed. Thoracic volume decreased gradually and $\mathrm{P}_{\text {box }}$ had to be decreased to maintain thoracic volume at a constant level. As we assumed a constant relationship between thoracic volume and thoracic recoil forces $\mathrm{P}_{\mathrm{C}}$ and thus no influence of HFJV on $\mathrm{P}_{\mathrm{C}}$, a smaller $\mathrm{P}_{\text {box }}$ necessary to maintain thoracic volume indicates an increase of lung recoil forces $P_{L}$.

A decrease in lung stability during high-frequency ventilation has been ascribed to injury of the lung epithelium [28] and to interference with surfactant release and surfactant activity [29]. However, the literature is not unanimous in this respect [30-36]. Besides these mechanisms low tidal volume ventilation at low lung volume may cause increasing atelectasis irrespective of ventilatory frequency. This will also cause an increase in $P_{L}$ [37].

We conclude from the correlation close to identity between both methods immediate after onset of HFJV that with the clamp off method the end-expiratory alveolar pressure can be estimated accurately. This conclusion implies that data in literature obtained with this method can be regarded as being accurate. There- fore, we used the data obtained by this method to analyse the effects of ventilatory parameters on alveolarto-tracheal pressure difference.

\section{Effects of ventilatory parameters on alveolar-to-tracheal pressure difference}

The end-expiratory alveolar-to-tracheal pressure difference increased when either ventilatory frequency or tidal volume was increased. Both changes in HFJV implied an increase in mean expiratory flow, either by shortening the expiratory time and keeping tidal volume constant or by increasing tidal volume and keeping expiratory time constant. When $\Delta \mathrm{P}$, clamp off was plotted against this mean expiratory flow a nearly identical linear relationship was found for increasing frequency and for increasing tidal volume. Thus, we concluded that the mean expiratory flow could be regarded as a common factor in the relationship between $\Delta P$, clamp off versus $V_{T}$ and $\Delta P$, clamp off versus frequency.

Beamer et al. [7] studied the end-expiratory alveolar-to-tracheal pressure difference during HFJV in a bellows with tubing as a test lung. In contrast to our results they found no influence of a changing frequency on the (alveolar) pressure in the bellows. When we assume that the jet ventilator of the authors delivered a tidal volume which was proportional to driving pressure and insufflation time, the mean expiratory flow over the expiratory phase will have been proportional to driving pressure times inspiratory to expiratory ratio. When these two variables remain constant, the mean expiratory flow is constant at varying frequencies, and frequency changes will not change pressure in the bellows. On the other hand the pressure difference will increase either by increasing driving pressure or the inspiratory to expiratory ratio. From the data presented by Beamer et al. we calculated a linear relationship between the alveolar-to-tracheal pressure difference and the mean expiratory flow over the expiratory phase irrespective of the ventilatory pattern. So, their results with a mechanical test lung turned out to be identical to ours.

The relationship between pressure difference over the airways and flow is determined by airway resistance. Airway resistance decreases when lung volume increases [19]. We found the end-expiratory alveolarto-tracheal pressure difference to decrease with increasing end-expiratory thoracic volume. Bryan et al. [8] found smaller differences between mean alveolar pressure and mean tracheal pressure when tracheal pressure and therefore lung volume increased during HFO in rabbits. They believed that choke points devel- 
op when lung volume is low which limit maximal expiratory flow. Accordingly, Simon et al. [13] found a larger difference between the mean alveolar pressure and the mean tracheal pressure at lower tracheal pressures during HFO in dogs. In addition in their study the pressure difference appeared to be dependent on body position, which we could not confirm. Most studies so far have dealt with mean tracheal and mean alveolar pressures and differences between the two rather than end-expiratory values as in our study. There is no general agreement as to whether mean central airway pressure underestimates $[4,9,12-16]$, overestimates [23] or equals $[20,25]$ mean alveolar pressure. Our study indicates that end-expiratory tracheal pressure above a certain level of mean expiratory flow underestimates end-expiratory alveolar pressure, the difference between the two being related to the mean expiratory flow rate and lung volume.

The difference between mean alveolar and mean tracheal pressure appeared to have a more complicated mechanism, especially in HFO where expiration is actively performed. This mechanism could include differences in inspiratory and expiratory airway resistance [13], the existence of a critical expiratory flow limitation [15], a non-linear pressure flow relationship [23], inertances of lung and thoracic wall [23, 38], parallel compliances in the airways [23] and for HFJV also differences in inspiratory and expiratory flow rates [23]. It is not known whether these factors influence the end-expiratory alveolar-to-tracheal pressure difference during HFJV. However, all these studies on alveolar pressure, including ours, presented a weighed mean of the alveolar pressures in all the different lung regions. The alveolar pressure in these regions may be distributed considerably inhomogeneously [38-40].

Therefore, from our experiments we have concluded that the end-expiratory clamp off method is an accurate method to measure the weighed mean of endexpiratory alveolar pressures and thus to determine the alveolar-to-tracheal pressure gradient during HFJV. We further concluded that this gradient depends linearly on mean expiratory flow rate for a given lung volume. As a consequence the relationship between the alveolar-to-tracheal pressure gradient $(\Delta \mathrm{P})$ and expiratory flow rate $\left(V_{E}^{\prime}\right)$ seemed to be governed by the aerodynamical equivalent of Ohm's law: $\Delta \mathrm{P} \simeq \mathrm{V}_{\mathrm{E}}^{\prime}$ $\times R$, where airway resistance $(R)$ is the derived variable, which also during HFJV was decreased when lung volume increased.

Acknowledgements. The authors are indepted to Mr. A. Drop and Mr. C. Geilman, Erasmus University Rotterdam, for their technical assistance, and to Dr. H. J.A. Wynne, Centre of Biostatistics, University of Utrecht, for the statistical analyses of the data.

\section{References}

1. Bergman NA (1969) Properties of passive exhalations in anesthetized subjects. Anesthesiology 30:378-387

2. Bergman NA (1972) Intrapulmonary gas trapping during mechanical ventilation at rapid frequencies. Anesthesiology $37: 626-633$

3. Rouby JJ, Simonneau G, Benhamou D et al. (1985) Factors influencing pulmonary volume and $\mathrm{CO}_{2}$ elimination during highfrequency jet ventilation. Anesthesiology 63:473-482

4. Armengol J, Jones RL, King EG (1985) Alveolar pressures and lung volumes during high-frequency oscillatory ventilation in dogs. Crit Care Med 13:632-636

5. Bancalari A, Gerhardt T, Bancalari E, Suguihara C, Hehre D, Reifenberg L, Goldberg RN (1987) Gas trapping with high-frequency ventilation: jet versus oscillatory ventilation. J Pediatr $110: 617-622$

6. Banner MJ, Gallagher TJ, Banner TC (1985) Frequency and percent inspiratory time for high-frequency jet ventilation. Crit Care Med 13:395-398

7. Beamer WC, Prough DS, Royster RL, Johnston WE, Johnson JC (1984) High-frequency jet ventilation produces auto-PEEP. Crit Care Med 12:734-737

8. Bryan AC, Slutsky AS (1986) Lung volume during high frequency oscillation. Am Rev Respir Dis 133:928-930

9. Eliasen K, Mogensen T, Andersen JB (1986) Peripheral airway pressure during high frequency ventilation. Acta Anaesthesiol Scand $30: 97-100$

10. Fletcher PR (1983) Alveolar pressures during high frequency ventilation. In: Scheck PA, Sjöstrand UH, Smith RB (eds) Perspectives in high frequency ventilation. Martinus Nijhoff, The Hague, pp $92-97$

11. Frantz ID, Close RH (1985) Elevated lung volume and alveolar pressure during jet ventilation of rabbits. Am Rev Respir Dis 131:134-138

12. Saari AF, Rossing TH, Solway J, Drazen JM (1984) Lung inflation during high-frequency ventilation. Am Rev Respir Dis 129:333-336

13. Simon BA, Weinman GG, Mitzner W (1984) Mean airway pressure and alveolar pressure during high-frequency ventilation. J Appl Physiol 57:1069-1078

14. Smith DW, Frankel LR, Ariagno RL (1988) Dissociation of mean airway pressure and lung volume during high-frequency oscillatory ventilation. Crit Care Med 16:531-535

15. Solway J, Rossing TH, Saari AF, Drazen JM (1986) Expiratory flow limination and dynamic pulmonary hyperinflation during high-frequency ventilation. J Appl Physiol 60:2071-2078

16. Sutton JE, Glass DD (1984) Airway pressure gradient during high-frequency ventilation. Crit Care Med 12:774-776

17. van Vught AJ, Versprille A, Jansen JRC (1986) Suppression of spontaneous breathing during high-frequency jet ventilation; influence of dynamic changes and static levels of lung stretch. Intensive Care Med 12:26-32

18. van Vught AJ, Versprille A, Jansen JRC (1987) Suppresion of spontaneous breathing during high-frequency jet ventilation; scparate effects of lung volume and jet frequency. Intensive Care Med 13:315-322

19. Dubois AB (1964) Resistance to breathing. In: Fenn O, Rahn H (eds) Handbook of physiology; a critical, comprehensive presentation of physiological knowledge and concepts. American Physiological Society, Washington DC, vol 1, section 3, Respiration: pp $451-463$

20. Benhamou D, Ecoffey C, Rouby JJ, Fusciardi J, Viars P (1984) Impact of changes in operating pressure during high-frequency jet ventilation. Anesth Analg 63:19-24

21. Gottfried SB, Rossi A, Milic-Emili J (1986) Dynamic hyper- 
inflation, intrinsic PEEP and the mechanically ventilated patient. Intensive Crit Care Digest 5:30-33

22. Pepe PE, Marini JJ (1982) Occult positive end-expiratory pressure in mechanically ventilated patients with airflow obstruction; the auto-PEEP effect. Am Rev Respir Dis 126:166-170

23. Perez Fontan JJ, Heldt GP, Gregory GA (1986) Mean airway pressure and mean alveolar pressure during high-frequency jet ventilation in rabbits. J Appl Physiol 61:456-463

24. Pfenninger J, Minder L (1988) Pressure-volume curves, static compliances and gas exchange in hyaline membrane disease during conventional mechanical and high-frequency ventilation. Intensive Care Med 14:364-372

25. Rouby JJ, Fusciardi J, Bourgain JL, Viars P (1983) High-frequency jet ventilation in postoperative respiratory failure: determinants of oxygenation. Anesthesiology 59:281-287

26. Wakkers PJM, Hellendoorn HBA, Op de Weegh GJ, Heerspink W (1975) Applications of statistics in clinical chemistry; a critical evaluation of regression lines. Clin Chim Acta 64:173-184

27. Versprille A, Jansen JRC, Schreuder JJ (1982) Dynamic aspects of the interaction between airway pressure and the circulation. In: Prakash $O$ (ed) Applied physiology in clinical respiratory care. Martinus Nijhoff, The Hague, pp 447-463

28. Man GCW, Ahmed IH, Logus JW, Man SFP (1987) High-frequency oscillatory ventilation increases canine pulmonary epithelial permeability. J Appl Physiol 63:1871-1876

29. Ennema JJ, Reyngoud D-J, Egberts J, Mook PH, Wildevuur ChRH (1984) High-frequency oscillation affects surfactant phospholipid metabolism in rabbits. Respir Physiol 58:29-39

30. Frantz ID, Stark AR, Davis JM, Davies P, Kitzmiller T (1982) High-frequency ventilation does not affect pulmonary surfactant, liquid, or morphologic features in normal cats. Am Rev Respir Dis 126:909-913

31. Kudoh I, Soga T, Numata K (1987) Effect of high-frequency ventilation on extravascular lung water volume in dogs. Crit Care Med 15:240-242
32. Mautone AJ, Condorelli S, Scarpelli EM (1987) Ventilation and pulmonary mechanics during high-frequency oscillation of immature lungs at birth. Crit Care Med 15:233-239

33. Obara H, Maekawa N, Hamatani S, Iwai S (1987) Effect of combined high-frequency oscillatory ventilation on rabbit alveolar type-2 cells. Crit Care Med 15:692-695

34. Truog WE, Standaert TA, Murphy J, Palmer S, Woodrum DE, Hodson WA (1983) Effect of high-frequency oscillation on gas exchange and pulmonary phospholipids in experimental hyaline membrane disease. Am Rev Respir Dis 127:585-589

35. Weinmann GG, Simon BA, Mitzner W (1984) Lung compliance changes on high-frequency ventilation in normal dogs. J Appl Physiol 56:506-512

36. Weinmann GG, Huang Y-C, Mitzner W (1987) Effects of highfrequency ventilation on lung mechanics at high transpulmonary pressure. J Appl Physiol 63:1544-1550

37. Nunn JF (1978) Applied respiratory physiology. Butterworths, London

38. Fredberg JJ, Keefe DH, Glass GM, Castile RG, Frantz ID (1984) Alveolar pressure nonhomogeneity during small-amplitude high-frequency oscillation. J Appl Physiol 57:788-800

39. Allen JL, Frantz ID, Fredberg JJ (1985) Regional alveolar pressure during periodic flow. $J$ Clin Invest 76:620-629

40. Allen JL, Frantz ID, Fredberg JJ (1987) Heterogeneity of mean alveolar pressure during high-frequency oscillations. J Appl Physiol 62:223-228

Dr. A. J. van Vught

Pathophysiological Laboratory

Department of Pulmonary Diseases

Erasmus University

P.O. Box 1738

NL-3000 DR Rotterdam

The Netherlands 